\title{
A retrospective study of patient outcomes and satisfaction following pinnaplasty
}

\author{
This article was published in the following Dove Press journal: \\ Patient Related Outcome Measures \\ 24 May 2016 \\ Number of times this article has been viewed
}

\section{Nicholas Hope' \\ Caroline P Smith' \\ Jim R Cullen ${ }^{2}$ \\ Neil McCluney ${ }^{2}$}

'Northern Ireland Medical and Dental Training Agency, Belfast, ${ }^{2} \mathrm{Head}$ and Neck Unit, Altnagelvin Area Hospital, Derry, Northern Ireland, UK
Correspondence: Nicholas Hope Northern Ireland Medical and Dental Training Agency, 42 Beechill Road, Belfast BT8 7RL, Northern Ireland, UK Email n.r.hope.05@aberdeen.ac.uk
Introduction: Up to 5\% of all children have prominent ears. Psychological distress and bullying adversely affect these children and can cause significant social exclusion. In times of austerity, cosmetic procedures such as surgical correction of prominent ears are felt to be an unnecessary cost to the health service.

Materials and methods: A retrospective case note review of all patients undergoing pinnaplasty was undertaken. Postoperative outcomes were compared against the Royal College of Surgeons of England standards. The Glasgow Benefit Inventory, a validated post-intervention questionnaire, was then posted out to all patients.

Results: A total of 72 patients were identified. Average age at procedure was 13 years. Eleven patients were above the age of 19 years. Twenty-eight patients were male and forty-four female. Sixty-two cases underwent bilateral pinnaplasty. No patients developed hematoma, and there were no readmissions within 30 days of surgery. Twenty-nine patients responded to the questionnaire (40\%), of whom 27 reported a positive impact on their psychosocial well-being with a mean score of 36 .

Conclusion: Pinnaplasty offers patients an opportunity to alleviate the psychological distress of bullying and harassment secondary to the appearance of prominent ears.

Keywords: bullying, Glasgow Benefit Inventory, hematomas, prominent ears, psychological distress

\section{Introduction}

Prominent ears is an important clinical condition affecting up to $5 \%$ of children. ${ }^{1}$ It is well known that children affected by cosmetic deformities of the external ear are more likely to be bullied, suffer from psychological distress, and subsequently play truant. ${ }^{2}$ Children with prominent ears are often bullied at school and are also subjected to teasing by family members. ${ }^{3,4}$ These children are not only more likely to be depressed, but they are also more likely to socially and economically disadvantage themselves by not attending education. ${ }^{3}$

Surgical correction of prominent ears is believed to date back as far as 1881 , when Ely ${ }^{5}$ first described the correction of prominent ears. ${ }^{6}$ Since then, there have been many surgical techniques described on how to perform pinnaplasty. Techniques can be broadly categorized into three groups. ${ }^{6}$ Excision techniques involve removing the skin and cartilage from the prominent ear to allow a more cosmetically favorable ear to be shaped. The second group involves suturing techniques to manipulate the antihelix. The third group - cartilage scoring techniques - is used to help mold the 
cartilage of the ear in a predictable fashion. Within each of these groups, there have been many operative procedures described. Modern practices can often involve combinations of the abovementioned techniques to enable the surgeon to achieve the best results in line with patient anatomy and expectation. Complications of pinnaplasty include hematoma, infection, suture extrusion, and poor cosmetic result. Alternatively, if a parent presents with an affected child before the age of 6 months, conservative measures can be attempted in the first instance. Owing to the relatively softer cartilage in the very young, specialized ear splints can be applied to achieve correction of the prominent ears.

In an economic climate whereby austerity is at the forefront of government policy in the UK, it is clear to most people that cosmetic procedures such as those used to correct prominent ears come under close scrutiny. For this reason, guidelines were introduced stating that all patients undergoing pinnaplasty within the National Health Service (NHS) should be under the age of 19 years at initial referral. ${ }^{3}$

In addition to surgery curing diseases and prolonging life, there is an ever-increasing focus on providing health care to improve quality of life. Quality of life is a broadbased concept that takes into account psychological and social aspects of health in addition to the physical aspects. A validated scoring system - the Glasgow Benefit Inventory (GBI) - has been used to determine the effectiveness of a clinical intervention and the subsequent impact it has had on an individual's life. ${ }^{7,8}$ It consists of 18 questions on a Likert scale rated from 1 to 5 . The pediatric version of the questionnaire has additional questions, all of which are answered by the guardian on behalf of the child. The answers from the questionnaire are entered into an algorithm giving the patient a total score from -100 to +100 . Several studies have tried to ascertain the success of pinnaplasty based on patient satisfaction using different scoring measures. In this study, we aim to assess the postoperative outcomes of those patients undergoing pinnaplasty and subsequently assess the impact of pinnaplasty on an individual's quality of life using the GBI.

\section{Materials and methods}

All patients undergoing pinnaplasty at a single center in Northern Ireland were identified over a 5-year period. All patients were referred to the ENT (ear, nose, and throat) outpatient department with a primary concern of appearance of the external ear. Only one case was referred following external trauma to the pinna. No cases were excluded. A retrospective case note review of all patients undergoing pinnaplasty was performed. Demographic details, procedure performed, and complications were documented. An anonymous GBI was posted out to all patients with a stamped addressed envelope included for return. After 2 weeks, those patients who had not responded were contacted via telephone to determine whether they would be willing to respond. As this was a retrospective study and did not alter the treatment of patients or their outcomes, the Professional Audit Department from the Western Health and Social Care Trust deemed ethical approval was not required. Patient participation in the study was entirely voluntary, with explanation and consent obtained prior to inclusion and completion of questionnaire.

Results were analyzed using SPSS Version 20. Where appropriate, the results were quoted as a mean with standard deviation.

The GBI questionnaire was extensively developed by Robinson et $\mathrm{al}^{8}$ in the field of otorhinolaryngology (Supplementary material). The questions were designed to take into account the total psychological, social, and physical well-being of a patient following operative intervention. In particular, this questionnaire aims to elucidate changes in health following procedures to improve quality of life rather than emergency operations or those for potentially fatal conditions. The questionnaire was developed and validated to show that surgical outcomes and postoperative patient satisfaction scores were closely related. The authors report five studies in which the GBI results were compared with independent measures of operative success. In one retrospective administration of the questionnaire at a mean interval of 4 years postoperatively for middle ear surgery, patient satisfaction scores were significantly higher in those patients in which the surgery had been a technical success as evidenced by an improvement in patient hearing. Patient response rate was $64 \%$ (113/181 patients). In another retrospective study by the team at a mean of 6 years following intervention for chronically discharging ears, a similar relationship was found between the technical success of the operation (cessation of ear discharge) and patient-reported outcomes. Again the response rate was comparatively high at $72 \%$ (138/192). Similar findings were reported in patients undergoing rhinoplasty and tonsillectomy, further highlighting the reliability of such a tool. The authors report in their findings that positive response bias had not been an issue as the responses were normally distributed without positive skews.

The Glasgow Children's Benefit Inventory (GCBI) was developed with similar findings. ${ }^{7}$ The format of development was similar to the previous GBI, whereby the questions may be answered by a guardian on behalf of the child. Validity 
Table I Demographic details of patients undergoing pinnaplasty

\begin{tabular}{ll}
\hline Age & \\
Child $(<\mid 4)$ & 6 I \\
Adult $(14+)$ & 1 I \\
Sex & 28 \\
Male & 44 \\
Female & \\
Side of operation & 1 \\
Right only & 9 \\
Left only & 62 \\
Bilateral & \\
\hline
\end{tabular}

of the results was maintained by using independent proven methods of measuring postoperative outcomes in children who had undergone procedures such as tonsillectomy and grommet insertion. Given that the scores of satisfaction were consistent across separate procedures, it was also felt to be a reliable tool.

\section{Results}

A total of 72 patients who underwent pinnaplasty were identified for inclusion in the study (Table 1). The age range of patients undergoing the operation was between 3 years and 37 years. The average age of patients was 12.7 years $( \pm 7.6)$. The median age was 11 years (interquartile range $7-16$ ). The mean age at survey was 16.2 years $( \pm 7.4)$. Eleven patients were above the age of 19 years at operation. Operative technique was dependent on patient anatomy and operating surgeon. There were no hematomas requiring drainage on primary admission. There was no readmission within 30 days postoperatively. Twenty-nine patients responded to the GBI questionnaire (40\%). The mean time to questionnaire distribution was 3.4 years (range 1-8 years). Ten guardians answered on behalf of a child, 19 were answered by the patients themselves. Of the respondents, $93 \%$ scored positively, with only two patients reporting negative outcomes. The scores are listed in Table 2. Mean overall score for all responding participants was $+36( \pm 27.4)$. When looking at the GBI in isolation, the mean reported scores for individual domains are as follows: for general health $+54( \pm 33.5)$, for social well-being $+16.6( \pm 27.8)$, and for physical health $+11.6( \pm 13.4)$.

Table 2 Mean reported GBI/GCBI scores postoperatively

\begin{tabular}{lllll}
\hline & $\begin{array}{l}\text { Total } \\
\text { score }\end{array}$ & $\begin{array}{l}\text { General } \\
\text { score }\end{array}$ & $\begin{array}{l}\text { Social } \\
\text { support }\end{array}$ & $\begin{array}{l}\text { Physical } \\
\text { score }\end{array}$ \\
\hline Adult (mean) & 33.9 & 54 & 16.6 & $1 \mathrm{I} .6$ \\
Child (mean) & 39.9 & $\mathrm{~N} / \mathrm{A}$ & $\mathrm{N} / \mathrm{A}$ & $\mathrm{N} / \mathrm{A}$ \\
\hline
\end{tabular}

Abbreviations: GBI, Glasgow Benefit Inventory; GCBI, Glasgow Children's Benefit Inventory; N/A, not applicable.

\section{Discussion}

To the best of our knowledge, this is the first study in Northern Ireland to evaluate the postoperative satisfaction of patients undergoing pinnaplasty. The very nature of this study is subjective, making robust analysis difficult. That said, the overall response of patients would suggest that pinnaplasty on the whole leads to positive health-related outcomes for patients.

Global health has traditionally been hard to define. ${ }^{9}$ There are numerous definitions that typically focus on the health of all people on Earth, with a view to improving equity between countries or encouraging initiatives from governments across the globe to help deal with common burdens of disease. On the whole, pinnaplasty is a cosmetic procedure aiming to relieve psychological distress. It is therefore more appropriate to discuss cosmetic ear surgery in the context of health-related quality of life.

Health-related quality of life is a more accepted term in the developed world and seeks to answer questions not only of mortality and life expectancy. It aims to place value on the quality of a change in health status that individuals place on certain conditions. ${ }^{10}$ This includes the physical, psychological, and social aspects of life. In relation to pinnaplasty, therefore, although patients will not necessarily come to physical harm because of their condition, the stresses of one's own appearance may be damaging psychologically. It is well known that children can be particularly susceptible to psychological trauma from harassment and bullying at school. $^{3}$

Our results are in keeping with current literature that those patients undergoing pinnaplasty experience positive outcomes on their health. Patients self-reported a biggest improvement in their general health. This is in keeping with the consensus that esthetic surgery is important in the global assessment of health and psychological well-being. ${ }^{11,12}$ It is interesting to note that there was a tendency toward the reporting of positive outcomes with regard to social wellbeing. It is hard to say exactly why this might be, but one may speculate that people may feel more comfortable in the company of others postoperatively because of factors related to self-consciousness. Slightly more surprising was the suggestion that patients undergoing pinnaplasty felt physically better postoperatively. This is hard to comment on, but the authors suggest that it may in fact be a result of the questionnaire itself. First to note is that there are only three questions in the physical health domain. This means there is the potential for any given answer to drastically skew the result. Further to this, the questions themselves 
may introduce a form of response bias. For example, one of the questions inquired about the frequency of attendances to the family doctor since the operation. Younger patients are healthier than the elderly, and following intervention it is hypothesized that the patient may not require further input from their general practitioner.

It is important to note, however, that two respondents (7\%) reported negative health effects following intervention. Unfortunately, the questionnaire does not contain a free text box for additional comments. On further questioning, one patient was dissatisfied with the cosmetic result following intervention. On looking at the responses contained within this questionnaire, the patient felt they had less selfconfidence, were more self-conscious, and more inconvenienced by their initial complaint. The second negatively scoring questionnaire suggested that the patient was not only more inclined to withdraw from social situations but also felt less self-confident. Unfortunately, we were unable to make contact with the patient to discuss this further.

In addition to the questionnaire results, we also note that we can validate our dataset further as it met current postoperative standards with regard to no hematomas requiring drainage and no patients being readmitted within 30 days following the operation in keeping with the Royal College of Surgeons of England guidelines. ${ }^{13}$

Songu and $\mathrm{Kutlu}^{14}$ found a high rate of patient satisfaction in children undergoing pinnaplasty. Of 67 children, 63 reported an increase in health-related quality-of-life outcomes (94\%). Furthermore, they found that not one patient reported negative outcomes. Braun et a ${ }^{15}$ studied postoperative outcomes in 62 patients with similar results. Using the GBI, the mean score in their cohort was 30.6. Hundred percent of adults who responded were satisfied with the esthetic result and $97.6 \%$ of parents were pleased with the outcome of their child's operation. Toplu et al ${ }^{16}$ evaluated postoperative outcomes and quality-of-life scores in both the adult and pediatric population. They recorded outcomes for 77 patients undergoing pinnaplasty using two separate techniques and also used the GBI and GCBI. They found when evaluated 3 months postoperatively, regardless of the operative technique, patients reported an increase in quality of life. The total scores reported in this study following administration of the questionnaire were similar to that of our own. Unlike our study, there is no reference to longer-term follow-up. In another study, Papadopulos et al used a variety of scoring methods to assess health-related outcomes following pinnaplasty in 81 patients. Three separate age groups were used for the analysis with children, adolescents, and adults, all reporting an improvement in health and psychological well-being. ${ }^{2}$

In our cohort, we received a comparable response rate of $40 \%$. Our study does, however, include well-documented biases. Responder bias is important to consider when evaluating the results of an intervention several years later. We do not know if those patients returning the questionnaire were fundamentally different from those who did not. The range of 1-8 years from the operation to receiving the questionnaire may also affect the results. Patients may better recall preoperative feelings if asked to complete the questionnaire soon after the operation. We also do not know if the $40 \%$ of respondents is representative of the whole group or if patients at the extremes are more likely to respond ie, highly satisfied or highly dissatisfied. In the case of children undergoing the procedure, it is the guardian who is answering on behalf of the child and we must take this into account when drawing conclusions from the data.

Another important issue to raise is the use of two separate questionnaires. The adult questionnaire often appears to be sent when a child reaches the age of 14 years; however, not all children mature at the same age. Even more difficult to assess is the decision regarding the questionnaire that should be administered in cases where a patient is operated on when he or she is aged 10 years and is being asked to evaluate the outcome $4-5$ years later.

\section{Conclusion}

Given the significance of psychological distress caused by prominent ears, it is clear that operative intervention has the potential to alleviate many problems associated with cosmetic deformities. Money is often at the forefront of objections to operations perceived as cosmetic. In a nationally funded health service such as the NHS, it can be easy to overlook the long-term consequences of short-term actions. The initial cost of performing an operation to improve prominent ears may in fact be a wise investment. For although the initial cost may be a financial burden to the tax payer, if the alternative is that a child is bullied, harassed, and subsequently suffers depression, this in itself can lead to a lifetime of health and social care issues. There is also the consideration of utilization of other NHS services in the future secondary to the psychosocial impact of bullying and low self-esteem, ie, counseling/psychological/psychiatric input. To this end, further studies into the economic viability of pinnaplasty would be invaluable to help determine the cost-effectiveness of this procedure within publicly funded health care. 


\section{Disclosure}

The authors report no conflicts of interest in this work.

\section{References}

1. Kelley P, Hollier L, Stal S. Otoplasty: evaluation, technique, and review. J Craniofac Surg. 2003;14(5):643-653.

2. Papadopulos NA, Niehaus R, Keller E, et al. The psychologic and psychosocial impact of otoplasty on children and adults. J Craniofac Surg. 2015;26(8):2309-2314.

3. ENT UK. Otoplasty Position Paper. 2010. Available from: https://entuk.org/sites/default/files/files/otoplasty.pdf. Accessed October 28, 2015.

4. Keery H, Boutelle K, van den Berg P, Thompson JK. The impact of appearance-related teasing by family members. J Adolesc Health. 2015;37(2):120-127.

5. Rogers BO. Ely's 1881 operation for correction of protruding ears. A medical "first". Plast Reconstr Surg. 1968;42:584.

6. Hackney F. Plastic Surgery of the Ear. Selected Readings in Plastic Surgery University of Texas; Dallas, TX, USA 2001:1.

7. Kubba H, Swan IRC, Gatehouse S. The Glasgow children's benefit inventory: a new instrument for assessing health-related benefit after an intervention. Ann Otol Rhinol Laryngol. 2004;113(12): 980-986.

8. Robinson K, Gatehouse S, Browning GG. Measuring patient benefit from otorhinolaryngological surgery and therapy. Ann Otol Rhinol Laryngol. 1996;105(6):415-422.
9. Koplan JP, Bond TC, Merson MH, et al. Towards a common definition of global health. Lancet. 2016;373(9679):1993-1995.

10. Healthy People 2020 [webpage on the Internet]. Foundation Health Measure Report: Health Related Quality of Life and Well Being. 2010. Available from: http://www.healthypeople.gov/sites/default/files/ HRQoLWBFullReport.pdf. Accessed January 06, 2015.

11. Meningaud J, Benadiba L, Servant J, Herve C, Bertrand J, Pelicier Y. Depression, anxiety and quality of life: outcome 9 months after facial cosmetic surgery. J Craniomaxillofac Surg. 2015;31(1):46-50.

12. Guyatt GH, Feeny DH, Patrick DL. Measuring health-related quality of life. Ann Intern Med. 1993;118(8):622-629.

13. Royal College of Surgeons of England [webpage on the Internet]. Commissioning Guide: Pinnaplasty. 2013. Available from: https://www. rcseng.ac.uk/healthcare-bodies/docs/published-guides/pinnaplasty. Accessed October 28, 2015.

14. Songu M, Kutlu A. Health-related quality of life outcome of children with prominent ears after otoplasty. Eur Arch Otorhinolaryngol. 2014;271(6):1829-1832.

15. Braun T, Hainzinger T, Stelter K, Krause E, Berghaus A, Hempel JM. Health-related quality of life, patient benefit, and clinical outcome after otoplasty using suture techniques in 62 children and adults. Plast Reconstr Surg. 2010;126(6):2115-2124.

16. Toplu Y, Sapmaz E, Firat C, Toplu S. Clinical results and health-related quality of life in otoplasty patients using cartilage resection and suturing methods. Eur Arch Otorhinolaryngol. 2014;271(12):3147-3153.
Patient Related Outcome Measures

\section{Publish your work in this journal}

Patient Related Outcome Measures is an international, peer-reviewed, open access journal focusing on treatment outcomes specifically relevant to patients. All aspects of patient care are addressed within the journal and practitioners from all disciplines are invited to submit their work as well as healthcare researchers and patient support groups.

\section{Dovepress}

The manuscript management system is completely online and includes a very quick and fair peer-review system. Visit http://www.dovepress. com/testimonials.php to read real quotes from published authors. 